\title{
Analysis on the China national science and technology awards programs: Features and trends
}

\author{
Shaogang Liao, Ying Pan \\ School of Public Finance and Public Administration, Jiangxi University of Finance and Economics, Nanchang, China, 330013 \\ Email address: \\ liaoshaogang@163.com (Shaogang Liao)
}

To cite this article:

Shaogang Liao, Ying Pan. Analysis on the China National Science And Technology Awards Programs: Features And Trends. Journal of Human Resource Management. Vol. 2, No. 1, 2014, pp. 22-26. doi: 10.11648/j.jhrm.20140201.14

\begin{abstract}
Through the empirical analysis on the achievements of the China National Science and Technology Awards programs from 2001-2009 based on the scientometrics, this paper discovers that the China National Science and Technology awards programs presents the following features:70\% of the National Science and Technology Awards programs are supported by the national task schedule; the first awarded author affiliations appear diversity characteristics, the educational level of the awarded authors increase rapidly, the awarded authors mostly are the young and middle-aged persons, the quantities and the proportions of female awardees are increasing gradually. The Chinese National Science and Technology awards programs have played very important roles on stimulating the enthusiasm of independent innovation of researchers.
\end{abstract}

Keywords: National Science and Technology Awards Programs, Awarded Achievements: Empirical Analysis, China

\section{Introduction}

In the system of science and technology awards programs in China, the national science and technology awards represent the highest honors of the Government Science and Technology Awards. It has a distinguished reputation with its rich material rewards, and a strong encouraging spirit in the scientific community. It has made outstanding contributions on innovating and stimulating the enthusiasm of researchers, and promoting the Chinese science and technology career [1]. In 1999, the State Council underwent major reforms on the national science and technology awards system, and promulgated the "National Science and Technology Awards Regulations". For the decade, Chinese science and technology awards programs have made considerable progress. The rewards system has been improved, and embarked on a standardized, institutionalized and legal track and become an important part of the national science and technology care. In this paper, the research object is based on the 2001-2009 awarded achievements of the National Science and Technology Awards Program, since the "National Science and Technology Awards Regulations" was promulgated. This paper uses the measurement methods of quantitative analysis, summing up the characteristics and laws of awarded achievements' main source, and author affiliations. This paper is to provide the policy basis for perfecting the national science and technology awards system.

\section{More than $70 \%$ of Awarding Programs Were Supported by the National Scheduler}

We can find from the statistics of the National Science and Technology Awards program from2001 to 2009 that more than $70 \%$ of awarded programs were supported by the national task schedule. The national task schedule in this paper refers to the national schedule (mainly including national research programs, "863"program, "973"program, etc.), ministry schedule, provincial schedule, and the national fund.(in Table1)

We can see from Table 1 that since the $21^{\text {st }}$ century, among the three awarded achievements of the national scientific research programs, the natural scientific awards program received the highest proportion supported by the government. The 257 items of awarded achievements were totally supported by the government. This is mainly because that the basic research and applied basic research, as the important part of natural science research have the high requirements of innovation, with the features of heavy investment, long-term cycle and high level innovation [2].The natural scientific research program could not be completed by the strength of individual researchers. It must be supported strongly by the National power [3].Although the proportion of awarded natural science research programs 
supported by the government was $100 \%$ each year, the absolute amount of the awarded programs was unstable, reflecting the instability of the basic research and applied basic research. $78.2 \%$ of the awarded technological invention programs were supported by the government, lower than the natural science awards, but higher than the technology progress awards. The awarded achievements of the Technological Invention Programs were required to have the proprietary intellectual property, proprietary brand, and capability of continuous innovation and need the strong support of the government. The proportion of the Awarded Technological Invention Programs, supported by the government, there appeared rising trend, and its absolute amount continuously increased, reflecting that the nation paid attention to the capability of independent innovation. The proportion of scientific and technological progress programs supported by the government is the lowest, only
$72.8 \%$ of the programs received supports from government. The reason is that the number of the awarded scientific and technological progress programs is much higher than the first two awarded programs. It shows that as the rapid development of the Chinese market economic system, transforming scientific and technological achievements into the enterprise market competitiveness has become the active choice of enterprises. And the values of attaching importance to science and technology popularization and applied scientific and technological achievements benefiting the society is being accepted by more and more scientists [4].However the absolute number and the proportion of the awarded programs per year is unstable. It indicates that the government hasn't reached a unified comment policy of whether awarding scientific and technological achievements should be undertaken by the government or the market [5].

Table 1. Statistics about the main source of the awarded achievements of the national science and technology programs.

\begin{tabular}{|c|c|c|c|c|c|c|c|c|c|}
\hline \multirow[b]{2}{*}{ Year } & \multicolumn{3}{|c|}{ Natural science awards } & \multicolumn{3}{|c|}{ Technological invention awards } & \multicolumn{3}{|c|}{ Technological progress awards } \\
\hline & $\begin{array}{l}\text { Total } \\
\text { awards }\end{array}$ & $\begin{array}{l}\text { The number of } \\
\text { national tasks* }\end{array}$ & $\begin{array}{l}\text { Proportion } \\
(\%)\end{array}$ & $\begin{array}{l}\text { Total } \\
\text { awards }\end{array}$ & $\begin{array}{l}\text { The number of } \\
\text { national tasks* }\end{array}$ & $\begin{array}{l}\text { Proportion } \\
(\%)\end{array}$ & $\begin{array}{l}\text { Total } \\
\text { awards }\end{array}$ & $\begin{array}{l}\text { The number of } \\
\text { national tasks* }\end{array}$ & $\begin{array}{c}\text { Proportion } \\
(\%) \\
\end{array}$ \\
\hline 2001 & 18 & 18 & 100 & 14 & 12 & 85.7 & 191 & 137 & 71.7 \\
\hline 2002 & 24 & 24 & 100 & 21 & 18 & 85.7 & 218 & 156 & 71.5 \\
\hline 2003 & 19 & 19 & 100 & 19 & 14 & 73.7 & 216 & 153 & 70.8 \\
\hline 2004 & 28 & 28 & 100 & 28 & 20 & 71.4 & 244 & 185 & 75.8 \\
\hline 2005 & 38 & 38 & 100 & 40 & 34 & 85.0 & 236 & 175 & 74.2 \\
\hline 2006 & 29 & 29 & 100 & 56 & 41 & 73.2 & 241 & 184 & 76.3 \\
\hline 2007 & 39 & 39 & 100 & 51 & 46 & 90.2 & 255 & 185 & 72.5 \\
\hline 2008 & 34 & 34 & 100 & 55 & 37 & 67.3 & 254 & 182 & 71.7 \\
\hline 2009 & 28 & 28 & 100 & 55 & 43 & 78.2 & 282 & 198 & 70.2 \\
\hline Total & 257 & 257 & 100 & 339 & 265 & 78.2 & 2137 & 1555 & 72.8 \\
\hline
\end{tabular}

\section{The First Author Affiliations of the Awarded Programs Appear Diversified}

The awarded national science and technology programs are all the "big science" programs. The majority of them are undertaken by several research institutes. Among all the institutes, the first author affiliation does the greatest contribution to the programs and is ranked first. In this paper, we divide these institutes into five types: universities, research institutes, enterprises, and industry and research cooperative programs. The first author affiliations of the awarded national science and technology programs from 2001 to 2009 are as follows in Table 2.

As we can see from table 2, universities are ranking first, having 695 awarded achievements. The second is industry and research cooperative programs which have 455 awarded achievements. We can find out that universities share the largest proportion in the industry and research cooperative programs, followed by the research units and enterprises if we subdivide the list of author affiliation. It is noteworthy that after "China science and technology awards yearbook" cancelled the statistics of industry and research cooperative programs in 2006, but did the statistics of universities, research institutes and enterprises. So in 2007, the awarded achievements of universities increased significantly. It also showed that universities were the main power in the industry and research cooperative programs. Since the new century, the number of awarded programs of universities increased significantly, fully showing the strong scientific research strength. Universities had gathered a lot of scientific research personnel, with a strong production capacity and profound technical reserves. Universities were the source of science and technology innovation. Their scientific and technological achievements led the direction of Chinese research and scientific competitiveness. The main birthplace of their scientific research achievements in China was the leading scientific research competitive [6]. Although universities were the main force of awarded author affiliations, they did not reach the monopoly. Research institutes and enterprises also were the prize-winners, respectively won 451 and 402 items. This showed that the first author affiliations who won the prizes appeared as a diversified trend, which more and more institutions participated in the science and technology innovation activities. The number of achievements of enterprises increased year by year, showing their increasing abilities of technology innovation and exploitation. This showed that enterprises had become the main subjects of technological 
innovation. The enterprises conducted the independent innovation and technology development, manufactured high-tech products according to the market demands, and improved the abilities of enterprises participating in market competition. The industry and research cooperative programs winning prizes showed that scientific research and technology development in China were mostly guided by the demands of the nation and markets. It paid close attention to the combination of manufacturing, learning and research, and to the promotion and profits of social economic development [7].

Table 2. National science and technology award winners in classification of statistical units from 2001 to 2009.

\begin{tabular}{|c|c|c|c|c|c|c|c|c|c|c|}
\hline $\begin{array}{l}\text { The organization } \\
\text { type }\end{array}$ & 2001 & 2002 & 2003 & 2004 & $\begin{array}{l}\text { Year } \\
2005 \\
\end{array}$ & 2006 & 2007 & 2008 & 2009 & Total \\
\hline Universities & 38 & 47 & 47 & 61 & 68 & 70 & 127 & 115 & 122 & 695 \\
\hline Research institutes & 49 & 46 & 33 & 45 & 54 & 47 & 62 & 56 & 59 & 451 \\
\hline Enterprises & 15 & 42 & 31 & 39 & 34 & 44 & 68 & 63 & 66 & 402 \\
\hline $\begin{array}{l}\text { industry and research } \\
\text { cooperative programs }\end{array}$ & 63 & 60 & 74 & 87 & 91 & 80 & - & - & - & 455 \\
\hline Else & 2 & 3 & 1 & 1 & 0 & 13 & 13 & 19 & 18 & 70 \\
\hline Total & 167 & 198 & 186 & 233 & 247 & 254 & 270 & 253 & 265 & 2073 \\
\hline
\end{tabular}

Data sources: According to the classification of "Yearbook of Chinese Science and Technology Awards" from 2002 to 2010, statistics in this table is only a common project, "-" indicates the absence of the statistical data.

\section{The Educational Level of the Authors Involved in the Awarded Programs Greatly Increased}

An education degree not only reflects the educational background of the awarded authors, but to some extent, it also represents their personal level of knowledge. The authors involved in the awarded national science and technology programs are the elite representatives of researchers and their educational level is significantly higher than the national scientific research personnel's average educational level. According to the statistics, from 2001 to 2009, the award winners holding a university degree and above were $90 \%$ of the awarded personnel, among which the winners holding graduate degrees or above were maximum, accounted for $55.2 \%$ of the total awarded personnel (table 3 ).

From the Table 3, we can see, that the absolute number and proportion of people awarded with graduate degrees are showing a rising trend since the new century, with the proportion being the highest since 2003. They have become the backbone of the award winning people, while the number and proportion of the other levels of award-winning staff are showing a downward trend. This shows that the people awarded had a high-level professional education, which has laid a solid foundation for them to be engaged in research in this area of expertise .The absolute number of awarded people with college degrees is unstable, but the proportion has been showing a downward trend. Since 2003, the proportion has fallen from first place to second place, indicating that undergraduate education can not meet the high level research projects needs, and there is an urgent need to upgrade their education degree. The absolute number and proportion of award-winning people with college education and below, have a more substantial decline. Most of them are older, and their contribution to the group receiving awards is very limited. As history goes, this part of the awarded people ratio will become lower and lower. From the proportion trend of the educational degree of the prize winners, we can find that only the proportion of awarded winners with graduate degrees shows a continuous increase, while the proportion of the awarded winners with the other three lower educational backgrounds shows a declining trend. In addition, the number of winners with university or higher education is stable at levels above 500, while the number of winners with college education or below is less than 200 . The trend of polarization is very obvious.

Table 3. the educational level of the prize-winners mainly involved in the awarded national science and technology programs from 2001-2009.

\begin{tabular}{|c|c|c|c|c|c|c|c|c|}
\hline \multirow{3}{*}{ Year } & \multicolumn{8}{|c|}{ Education degree } \\
\hline & \multicolumn{2}{|c|}{ Master degree } & \multicolumn{2}{|c|}{ Bachelor degree } & \multicolumn{2}{|c|}{ College degree } & \multirow{2}{*}{$\begin{array}{l}\text { others } \\
\text { Amount }\end{array}$} & \multirow[b]{2}{*}{ Percentage $(\%)$} \\
\hline & Amount & Percentage $(\%)$ & Amount & Percentage $(\%)$ & Amount & Percentage $(\%)$ & & \\
\hline 2001 & 547 & 36.3 & 795 & 52.9 & 91 & 6.1 & 71 & 4.7 \\
\hline 2002 & 625 & 36.8 & 822 & 48.4 & 100 & 5.9 & 151 & 8.9 \\
\hline 2003 & 813 & 49.3 & 715 & 43.3 & 86 & 5.2 & 37 & 2.2 \\
\hline 2004 & 1097 & 52.7 & 777 & 37.3 & 97 & 4.7 & 112 & 5.3 \\
\hline 2005 & 1222 & 58.8 & 740 & 35.7 & 87 & 4.2 & 28 & 1.3 \\
\hline 2006 & 1343 & 62.1 & 717 & 33.1 & 73 & 3.4 & 30 & 1.4 \\
\hline 2007 & 1368 & 60.9 & 733 & 32.6 & 111 & 4.9 & 36 & 1.6 \\
\hline 2008 & 1426 & 64.2 & 709 & 31.9 & 57 & 2.6 & 28 & 1.3 \\
\hline 2009 & 1453 & 63.9 & 713 & 31.3 & 84 & 3.7 & 23 & 1.1 \\
\hline Total & 9894 & 55.2 & 6721 & 37.5 & 786 & 4.4 & 516 & 2.9 \\
\hline
\end{tabular}

Data sources: According to the classification of "Yearbook of Chinese Science and Technology Award" from 2002 to 2010, statistics in this table is only a common project. 


\section{The most Awarded Researchers Are the Young and Middle Aged Researchers}

Age is one of the most important indicators showing the researchers' comprehensive quality including research ability, and market development ability. In the past, according to the Seniority-Based System and Matthew effect, the prize-winners were mostly elder persons. Even in the $1990 \mathrm{~s}$, the prize winners over the age of 60 were more than $30 \%$ of the winners, reflecting middle-aged and young researchers being in subordinate status, not the one's with all the responsibility of the scientific research job [8].

As the numbers of young and middle-aged scientific researchers have grown, the prize-winners age has gradually become younger. According to the statistics of the prize-winners' ages from year 2001 to 2009 (See table four) ,the average age of the prize-winners was 45.2. There were 10828 awarded persons whose ages were under 45 , $60.4 \%$ of all the winners. From the statistics the winners whose ages were from 36 to 45 years were the largest number of the all winners with the high percentage, whose number and percentage increased continuously. It explained the scientific researcher in this age group had already become the main prize-winners. However, the prize-winners under the age of 35 increased, with its proportion declining gradually, the largest number of which appeared in 2004 and then declined. The number and proportion of prize winners from age 46 to 55 were in an increasing trend, with a small increase. The prize-winners in this age group were the directors of programs, and were the backbones, whose contribution to the awarded achievements always was the greatest. The number and proportion of the prize-winners over 56 years old declined. They mainly undertook the advisory role, with less practical contribution [9]. Research showed that the best age of researchers is from 25 to 45 , whose peak was about 37[10] .At the present, the average age of the researchers to the awarded national scientific programs is close to the peak.

According to the analyses on the age structure of the researchers of the awarded national scientific and technological achievements from 2001 to 2009 , we can find that the age structure of researchers of the awarded national scientific and technological programs had turned from the old unimodal independent structure (mostly in56-65 age group)in 1990's to the new unimodal independent structure (mostly in 36-45 age group) at the present, which peak age declined 20 years. This shows that the good scientific research teams with young and middle-aged researcher as the backbone and young, middle-aged and old researchers cooperating well together have been formed.

Table 4. 2001 to 2009 national science and technology award winner age structure of the main achievements of the persons involved.

\begin{tabular}{|c|c|c|c|c|c|c|c|c|c|c|}
\hline \multirow{3}{*}{ Year } & \multicolumn{10}{|c|}{ Age groups } \\
\hline & \multicolumn{2}{|c|}{ Younger than 35} & \multirow{2}{*}{$\begin{array}{l}35 \text { to } 45 \\
\text { Amount }\end{array}$} & \multirow[b]{2}{*}{ Percent (\%) } & \multicolumn{2}{|c|}{46 to 55} & \multicolumn{2}{|l|}{56 to 65} & \multicolumn{2}{|c|}{66 and above } \\
\hline & Amount & percent $(\%)$ & & & Amount & Percent (\%) & Amount & Percent (\%) & Amount & Percent (\%) \\
\hline 2001 & 317 & 21.1 & 555 & 36.9 & 237 & 15.7 & 263 & 17.5 & 132 & 8.8 \\
\hline 2002 & 354 & 20.8 & 639 & 37.6 & 254 & 15.1 & 335 & 19.7 & 116 & 6.8 \\
\hline 2003 & 317 & 19.2 & 660 & 40 & 273 & 16.5 & 257 & 15.6 & 144 & 8.7 \\
\hline 2004 & 471 & 22.6 & 836 & 40.1 & 382 & 18.3 & 224 & 10.8 & 170 & 8.2 \\
\hline 2005 & 375 & 18.1 & 919 & 44.2 & 391 & 18.8 & 206 & 9.9 & 186 & 9 \\
\hline 2006 & 408 & 18.9 & 991 & 45.8 & 408 & 18.9 & 210 & 9.7 & 146 & 6.7 \\
\hline 2007 & 367 & 16.3 & 982 & 43.7 & 552 & 24.5 & 196 & 8.8 & 151 & 6.7 \\
\hline 2008 & 275 & 12.4 & 970 & 43.7 & 645 & 29.1 & 168 & 7.5 & 162 & 7.3 \\
\hline 2009 & 363 & 16 & 1029 & 45.3 & 589 & 25.9 & 163 & 7.2 & 129 & 5.6 \\
\hline total & 3247 & 18.1 & 7581 & 42.3 & 3731 & 20.8 & 2022 & 11.3 & 1336 & 7.5 \\
\hline
\end{tabular}

Data sources: According to the classification of "Yearbook of Chinese Science and Technology Award" from 2002 to 2010 , statistics in this table is only a common project.

\section{The Number and the Proportion of Female Winners Are Increasing Gradually}

Scientific research is a dull work, and most researchers are male. In the past, there were few females winning the National Science and Technology Awards Programs. However, with the increase of female researchers, more and more women won the Chinese National Science and Technology Awards. According to statistics from 2001 to 2009, 2,250 women won the National Science and Technology Awards, accounting for 14.2\%.It's higher than the proportion in the Ninth Five-year-plan period which was $13.9 \%$. Looking from the absolute number of the prize winners, female prize winners increased. Their numbers increased from 217 in 2001 to 352 in 2009.After dropping, the percentage of the female prize winners went up. The highest percentage was $15.5 \%$ in 2009. The male prize-winners increased overall. But the number of the male winners in 2005 decreased by 13, compared with that in 2004.The male's percentage decreased since 2005. It indicated that the number and proportion of females who won the National Science and Technology Awards increased gradually. The declining trend of female prize-winners was changed during the ninth five-year-plan period. 


\section{Discussion and Conclusions}

After a major reform of the national science and technology awards system, and the "regulations on national science and technology awards" were carried out, the achievements of the awarded national science and technology programs, showed new features and changes. Through the quantitative analysis of the achievements of the awarded national science and technology programs from 2001-2009, we can find the $70 \%$ of the awarded programs were supported by the government, among which $100 \%$ of the natural science awarded programs, $78.2 \%$ of the awarded technological invention programs and $72.8 \%$ of the awarded technological progress programs got the supports of all kinds of national plans. The first author affiliations presented diversified development trends, the universities ranking first, production-teaching-research combination programs ranking second, scientific research institutions and enterprises also accounting for a significant proportion. More and more institutions participated in the scientific and technological innovation activities. The educational level of the main researchers of the awarded programs increased rapidly, among which the awarded persons having the bachelor degrees or above were accounted for $90 \%$.The prize-winners who have a Master Degree were the most, accounting for $55.2 \%$ of all the prize-winners.

The age of National science and technology award winner gradually reduced, forming a good scientific research echelon combination of youth, middle-aged and old-aged. The number and proportion of female winners increase gradually, changing the overall decreasing trend of female winner numbers and the proportion in the past.The main researchers average age of the awarded programs decreased gradually. The fine scientific research teams which the young and middle-aged researchers were the backbone, and young, middle-aged and older researchers cooperated with each other had formed rapidly. The female awarded researchers' proportion increased. The declining trend of the number and percentage of the awarded female researchers during the Ninth five-year plan period was changed.

Because this paper is based on the statistical data analysis of the awarded national science and technology programs during 2001-2009, the research results only reflects the characteristics and changes of this period.The related predictions need to be tested by practice. And because of the limited length of the article, this paper does not conduct the detailed analysis of the National Natural Science Awards, Technological Invention Awards and the Technological
Progress Awards respectively. It is left to do further research in the future.

\section{Funding}

The author received support from jiangxi province development plan.fund for visiting scholar

\section{References}

[1] KunlunYao, 2008.Science and technology awards

[2] summary. Beijing: Science press: 128 .

[3] Suhua Zhong, Yankun Wang. 2007.The national science and technology plan and scientific and technical prizes. Beijing: Science press:32

[4] Jianxin Yan, XuKun Wang. 2008.China's national natural science and its reward strength analysis.science and science Technology managemen 11:5-9.

[5] Shuhua Zhong. 2008. the empirical analysis of The national science and technology plan independent innovation achievement award by the state science and technology. China science fund 6: 354-363.

[6] Huaian Wei, Xiaojun Hu. 2007.the economic efficiency analysis of the national science and technology award winner results. Scientific research management 28: 146-151.

[7] Futao Wang,2006 transformation and application analysis of the national science and technology award of achievements. The China science and technology BBS 4: 32-35.

[8] Junping Qiu,Chunhui Tan,Tingxiao Wen,2006. national science and technology awarding project measurement analysis in 2000-the 2004. Technical management research 2: $39-41$.

[9] Gang Liu,2003. "Ninth Five-Year Plan" national three awards for science and technology review and analysis. The China science and technology BBS 1: 96-100.

[10] Huaian Wei, Shuhua Zhong,2008. the age of the personnel structure analysis of the national science and technology award winner.Science and Technology Progress and Policy 25: $180-182$.

[11] HongzhouZhao.1984.Ability to learn in science. Beijing: Science press: 92

[12] The office of National awards for science and technology. the yearbook of China science and technology awards (2002-2010). Beijing: Mechanic industry Press, 2002-2010. 